\title{
Making a career in PESP in the corporatized university: Reflections on hegemony, resistance, collegiality and scholarship
}

For pessimists who believe that a corporatized university is no university at all, the university has changed for the worse. For optimists, well, for optimists, the battle is still joined. (It is up) to academicians and students to define the strategies and objectives for reclaiming the university. This is an important and honorable task. Universities are one of the central pillars of civil society. The core values and mission of the university must be sustained if the university is to fulfill its traditional role of learning, scholarship, and service. A fully corporatized university is only a shell of a university, and the task facing the academic community is to ensure that the inner core as well as the outer shell are preserved. If academics do not attend to the governance of their own institutions, who will? (Henry Steck, 2003, p81)

\section{Introduction}

I want to begin with this quote from Henry Steck, because it expresses for me more succinctly than I can myself some of my own core beliefs. I identify as one of Steck's optimists. While Steck's reference is to universities in the United States, I believe the challenge of corporatization is not limited to North America alone but is a global phenomenon. I believe along with Steck that the traditional role of the university, as a central pillar of civil society, of learning and scholarship in the service of the public and common good, is one that is worth preserving. And, furthermore, I believe this role is in grave and mortal danger, even greater than it was ten years ago when Steck penned this paper. I agree with Steck that the source of this danger is what he calls corporatization and that the corporatized university is indeed the mere shell of a university. And I believe it is up to us, the university's scholars, to resist corporatization and to reclaim its traditional role. But how might we engage in this important and honourable task AND build successful careers as university academics in PESP? This is the central question of my Scholar Lecture today. 
The idea of the Scholar Lecture we introduced to this BERA PESP SIG is borrowed from our cousins across the Atlantic, the AERA SIG in Research on Instruction and Learning in Physical Education. There, the Scholar Lecturer typically reflects on her or his own professional and sometimes personal experience to illustrate a topic. I intend to stick with this idea of the Scholar Lecture today. I do so because I think it is important to write ourselves in to our analyses as much as it is appropriate and necessary. The process of corporatization of the university has greatly accelerated during my career as an academic. Like most of you here today, I am living the process. I've seen close up what corporatization looks like, and experienced what it feels like. Indeed, I have in various ways both contributed to this process and sought to undermine it. So it would be disingenuous of me to discuss the topic as if I was a disinterested and uninvolved bystander.

Having said this, there are particular responsibilities that come with this need to write oneself in to a process. There is in particular a balance to be struck between honesty on the one hand and sensitivity on the other. And then there is the issue of the fallibility of human memory and the distinct possibility that people will remember the same events differently. So with these caveats in mind I will provide you with a very brief overview of my own career as a PESP academic and in the course of doing so make some observations on our field within the academy before moving on to consider the extent to which the hegemony of corporatization might be challenged and subverted, the kinds of resistance that can and should take place, and the central importance of collegiality and scholarship to the sustainability of the university as an institution of higher learning.

\section{A brief biography}

My first academic appointment was to the University of Queensland from 1984 to 1989, after completing a doctorate at Loughborough University. From UQ I moved to Deakin and stayed there until 1994. I've written recently about some aspects of my Deakin experience in Tinning and Sirna's edited book on education, social justice and the Deakin diaspora (see Kirk, 2011). My career then began to resemble a circle when I returned to UQ in 1995 as Professor. I returned to the UK and to Loughborough to close the circle in November 1998 to take up the Beckwith Chair in Youth Sport, an externally funded full-time research role within the Institute for Youth Sport, a role I hadn't actually applied for. I stayed at 
Loughborough until 2005, from 2000 having taken up the professorial post I originally applied for which was in the School of Sport and Exercise Sciences. In 2005 I broke the circle by becoming Dean of the Carnegie Faculty of Sport and Education at Leeds Met. The sudden (and forced) resignation of the Vice Chancellor in January 2009, just as I had become Pro Vice Chancellor for Research at Leeds Met, precipitated my own departure in May 2009 to my current post as Alexander Chair in Physical Education \& Sport at the University of Bedfordshire.

So my career as a PESP academic has spanned a 30 year period between 1982 (when I began a doctorate and part-time teaching assistantship at Loughborough) until 2012 where I am in my fourth post as full professor and also have a role as Director of a Research Institute at the University of Bedfordshire. As I have written in other contexts, we have witnessed the dramatic expansion of research activity in PESP - evidenced not least in the successful growth of this PESP SIG at BERA - and our increasing consolidation as an academic field of study in the university, while at the same time observing serious threats to the futures of both school physical education and physical education teacher education, fields of practice that our research seeks to inform and develop. These interestingly contradictory developments should alert us immediately to the complex circumstances in which we work and kinds of analyses we need to undertake in order to make sense of possibilities and probabilities for developing an academic career in PESP within the corporatized university.

\section{What is corporatization of the university?}

Steck (2003) provides the following definition of the corporatized university.

"The corporatized university is defined as an institution that is characterized by processes, decisional criteria, expectations, organizational culture, and operating practices that are taken from, and have their origins in, the modern business corporation. It is characterized by the entry of the university into marketplace relationships and by the use of market strategies in university decision making." (p74)

Steck makes nine points in elaboration of this definition (see also Tuchman, 2009). First, while he accepts that the elements of corporatization are not new, he suggests that there 
has been in the past two decades a "quantum leap" in corporate practices and culture within the university. Second, he argues that many university administrators and leaders and indeed some academics actually see the widespread prevalence of corporate practices as good and desirable. Third, and consequently, the university looks increasingly to businesses for operational guidance and as a source of solutions to organisational problems. Fourth, such is the prevalence of corporate practices that we can no longer argue that it is as if universities are businesses; they are, in fact, businesses.

Fifth, the criteria for the appointment of new academic leaders are changing and increasingly include entrepreneurial and management training and skills. Sixth, the university has lost its franchise as new, for-profit organisations offer academic qualifications in specific fields and contribute to the creation of a market and the need to develop and maintain a 'brand' (Helmsely-Brown \& Goonawardana, 2007). Seventh, the university is forming highly interdependent partnerships with other businesses and so increasingly sharing their commercial interests. Lieberwitz (2005) and Silvey (2002) provide examples of how these new business interests can be in conflict with academic values, an issue I will come back to in a moment.

Eighth, the nature of academic work is changing from collegial to hierarchical, often characterised as 'managerialism' (Meyer, 2002), and there is an increase in short term and part-time contracts and other forms of 'flexible' working practices in order to reduce the cost of academic work, an arrangement that adversely affects women disproportionately. Ninth, the university's mission shifts from one that serves broader public goods and interests to become one that serves sectional interests and generates profit (see also Lieberwitz, 2005).

In this characterization of the corporate university we can find clear evidence of the neoliberal project at work (Gray, 2002), perhaps most strongly in the changing relationship of the student to the university and how the student is implicated in the funding of the university. Within the corporate university the possession of a university degree shifts from being a public to a private good, and so therefore responsibility rests with the student and 
her or his family to make a private investment through the payment of tuition fees. In this context, the student is recast as a consumer or a customer. Steck (2003) suggests that

\footnotetext{
"if the notion that the customer is always right is obeyed, (this) reverses the relationship between student learner, teacher, and curriculum. As this notion gains currency - whether by decisions on campus or by the impact of information technology in the larger culture - the university will come to be regarded by students as simply a service provider, a convenience store for credentialing or self-enrichment." p76
}

Indeed, it might be argued that the commercialisation of the campus, with its branded outlets for clothing, food and coffee, and recreation, is an obvious tangible sign of the corporate university as a service provider, one that is clearly attractive to many students and some faculty. And yet, as Fiegenbaum (2007) suggests, within the corporatized university and in line with the neo-liberal project, the consumer-student is constructed as rational economic decision-maker, as someone whose decisions are narrowed to the link between choice of degree course and prospects within the job-market. As such, she reasons, students are much less likely than formerly to engage with any form of critical pedagogy and to value scholarship, a matter that is germane to our discussion here.

\section{Experiences of corporatization: principles and pragmatism}

I want to ground and illustrate Steck's account with reference to some of my own experiences of corporatization, focusing on a number of specific aspects drawn from episodes at Deakin, Loughborough and Leeds Met. I do this to show that our relationship to corporatization is rarely unambiguous and clear cut. There are times when pragmatism is required, and others where a principled stand needs to be taken. These examples also give me an opportunity to consider when it might and might not be possible to challenge the hegemony of corporatization and so prepare the ground for the analysis in the second half of this lecture, about the kinds of resistance that might take place, and the central importance of collegiality and scholarship to the sustainability of the university as an institution of higher learning. 
Deakin: collegiality, managerialism and the realities of university reorganisation I went to Deakin University in 1989 to immerse myself in what I perceived to be a community of socially critical scholars of education. The Deakin I met when I arrived had shed its teachers' college culture for the most part and the Faculty of Education was selfconsciously democratic and collegial in its structures and processes - indeed, McTaggart's (2011) piece in the Deakin Diaspora book talks about 'leftist hegemony'. A good example he gives was the election rather than appointment of 'Heads of Centres'.

A re-organisation of the university did not begin in earnest until 1992 when Deakin acquired three further campuses in metropolitan Melbourne which had been multi-campus Victoria College to add to another campus acquired in an earlier merger with Warnambool College. There were significant units of teacher education and physical education and sport sciences located on these Melbourne campuses. While there was a consultation process between the VC and academics over a structure for this new multi-campus university, it soon became clear that the collegial culture of the Geelong-based faculty would not survive; there would be no more electing Heads within a bureaucracy of appointed 'managers'.

One of the consequences of this re-organisation of Deakin was that I moved from the Faculty of Education based in Geelong to a new School of Human Movement over 100 kilometers away based at Burwood in Melbourne. My closest colleagues in physical education, eg. Richard Tinning and John Evans, did not move to the new school. I recall being frustrated with what I saw as a lack of willingness on the part of the critical pedagogues of the Faculty of Education to face reality and play a smarter game of institutional politics. However much I regretted the end of the 'old Deakin' (as I saw it), my conviction was that the better place for physical education to grow and develop was in the new School of Human Movement, despite its managerial and hierarchical culture inherited from the former Victoria College. This experience was influential in shaping my ongoing and current belief that PESP is more likely to thrive in a department or school of kinesiology than in education, a view regrettably that many of my Geelong-based colleagues did not share.

Loughborough: academic and business values 
When I spoke about my experience of Loughborough and the IYS in the AERA SIG Scholar Lecture in 2003 I saw it then as serendipity gone wrong and a promise unfulfilled (Kirk, 2003). I am more inclined now to understand what happened as a constituent aspect of corporatization and more specifically as an outcome of forming a partnership (in this case between the Youth Sport Trust and the university) that was framed by a business rather than an academic logic. To be sure, the YST was and remains a 'charity', but there is no question in my mind that it ran as a business given its close association with Sir John Beckwith, its founder and millionaire property magnate. I understood perfectly well at the time that the YST had an important loyalty to its sponsors and funders. This made perfect business sense. But it also set the stage for a clear clash of cultures, between the YST's need to please profit-driven sponsors and the university's need to respect the evidence produced by research.

What I began to better understand as time progressed was just how central corporate logic was to the university as well as the YST. Given this logic, the types of requests being made of me began to make more sense. What I ultimately had to come to terms with was whether I could work with integrity as an academic whose job is in part to conduct quality research or from a position within a business relationship aiming to promote particular programs and products. For me, the idea (for example) of having to report only the positive aspects of our research - it was explained to me that any negative findings would upset a sponsor - was counter to what I know about having integrity in my work. And while I would have expected and hoped that my institution would support the need for integrity in research, I better understand now why that was difficult for them to do. After all, Sir John was (as I understood it) the university's single biggest private donor of funds at that time.

\section{Leeds Met: marketization and branding}

While there is much I could say about the process of corporatization at Leeds Met, I want to focus in this case on how a university might approach the issue of marketization through the controversial process of branding. We need to recall, first, that additional student tuition fees of up to $£ 3000$ per annum had been mooted and were about to become a reality by 2005. Vice Chancellor Simon Lee was on record as a vocal opponent of student tuition fees, recognising fees erode the university's role as a provider of public rather than private goods. 
However, in response to the reality of the new fee regime, he argued that the university should charge the lowest possible fee ( $£ 2000)$ and rely on its sheer size to produce the income needed to run the organisation. And to continue to fill places on courses, the university had to sell itself as a place of quality for higher education.

The process of branding the university with the name of the Carnegie faculty was fascinating for me to observe. Probably the most potent branding device, for me, was Vice Chancellor Lee's use of the Carnegie rose. The rose consists of a number of bodies of students in gymnastic poses to form the petals and the stem, sometimes set out in the university's signature colours of purple and green. The rose symbolised Yorkshire, and so made an association between the university and place. Lee would explain that the petals and stem were images of students 'stretching themselves' in their pursuit of learning.

I do not know whether or not this particular marketing device prompted students to come to Leeds who otherwise might have gone elsewhere. This example, along with the Deakin and Loughborough examples, does raise for me a dilemma of corporatization of the university; if (in the case of Leeds Met) the market is a reality (however much it exists in a particular form in higher education in England), how is it possible to respond with integrity to the challenges it poses? Vice Chancellor Lee had engaged the university in a central process of corporatization, ie. branding, in order to achieve a commendable and common good, which was to charge the lowest tuition fee possible. Is creating a brand a valid and acceptable response, or not? If not, what are the alternatives?

\section{The hegemony of corporatization and prospects for resistance, collegiality and scholarship} In responding to this question of alternatives, we need to note first, according to Gramsci (1971), that any hegemonic order exists as a contingency. It is in other words always in need of maintenance and it is never so firmly established that its influence is absolute. Consistent with this view of hegemony, Kwiek (2001) concludes that the university remains in a process of "revolutionary change" of which corporatization may not be the inevitable end-point. Steck $(2003, p 74)$ goes on to add that for all of the signs of corporatization, "the academic culture is still present. There are strong continuities" between the present and the past that suggest the hegemony of corporatization, while pervasive, is not set in stone. 
On the basis of this understanding of hegemony, I identify, as I said earlier, as one of Steck's optimists. But, if we are to be optimists, what is the basis of our optimism? If it is merely nostalgia or a fear of change, then this in my view is no basis for action. Objection to corporate practices based on nostalgia or fear will not alter the perceptions of the growing cohorts of academic leaders in universities who view corporatization as a "legitimate, necessary, desirable, and positive good thing" (Steck, 2003, p75). Instead we need to have a clear sense of what forms of resistance are possible, desirable and legitimate for academics to engage in.

Such has been the profound effects of corporatization on the university that many of us find it difficult to imagine resisting in any fashion, or see the suggestion that we might as somewhat reckless and highly risky. And certainly, the possibility of resistance to the hegemony of corporatization needs to be thought through carefully. My own view is that the form of resistance needs to be organic to our work as academics. There are two related issues to consider here. First, drawing on Freire's (1990) view that the objectification of knowledge and its hierarchical transmission from teacher to learner is a method of oppression, regardless of its 'content', Heyman (2000) has argued "if knowledge is seen as a cooperative project, rather than an object or commodity, then students must be regarded as partners in education, rather than consumers of it" (p301). In other words, authentic engagement with knowledge and genuine learning are unlikely outcomes of a process that considers teaching and learning to be at root a financial transaction within a market. Secondly, this perspective of Heyman's is strongly supported by recent critics of the consequences of the neo-liberal project, such as the selfish individualism of some bankers, each critic calling for new ways of engaging in collective democratic processes (Hutton, 2010; Dorling, 2010; Judt, 2010).

For me, collectivism and collegiality go hand in hand. Collegiality involves recognition of what it is we have in common rather than what makes us different. In contrast, and consistent with the neo-liberal project of individualism, I suggest corporatization has eroded our sense of collegiality. But it is our capacity to act together, with shared values and goals, that is crucial to appropriate resistance to the hegemony of corporatization. I am not 
thinking here of the old fashioned trade union concept of solidarity and far less of the tactics of 'placard protests', 'work to rule' and 'withdrawal of labour'. While these may be appropriate to the factory floor in my view they have no place within the academy. The notion of touchstone, developed by Australian philosopher Jim Walker to find shared interests within a diverse field of study such as education, is a useful concept in this context of collegiality. What are the touchstones of academic work, the experiences and circumstances that provide us with a shared identity?

The cornerstone of our shared identity as academics and of our collegiality is, in my view, scholarship. I use the term here consistent with the work of Ernest Boyer (1990) in Scholarship Reconsidered. Boyer sees scholarship as the overarching feature of academic work, within which he suggests there is a scholarship of discovery, a scholarship of integration, a scholarship of application and a scholarship of teaching. Each of these forms of scholarship, insists Boyer, must have parity of esteem. Scholarship involves the generation of new knowledge, but it also requires us to bring existing knowledge together into new and insightful configurations, to use knowledge to inform action, and to inspire the desire to learn in students. Scholarship also requires that we approach these tasks with a particular attitude, one that involves open-mindedness, fairness, generosity and integrity. Moreover, this attitude recognises that scholarship is never a solo enterprise; it is a deeply interdependent and collective activity. Each one of us as academics does indeed stand on the shoulders of giants.

So what are the prospects for resistance to the hegemony of corporatization? I believe they are high when we understand that such resistance is an inevitable outcome of our work as academics, such as our respect for the weight of evidence and our careful generation, integration, application and dissemination of knowledge. This is not merely an ideological objection to corporatization and its many negative effects on the university, a mere negation of one position by another. It is instead a positive statement, that to uphold the values of academic work which has scholarship as its corner stone is to insist on the incompatibility of the corporation and the university. The bottom line for the corporation is profit; the university exists to serve the common good, prudently mindful of, but not governed by, its financial situation. 
Resistance is manifest in part then by doing the best academic work we can, by generating new and valuable knowledge and by seeking to put that knowledge to work not just through our teaching (though this is a core responsibility of academics) but also through our willingness to engage as public intellectuals with the issues and problems that most benefit most people. Resistance is also manifest in upholding the values of open-mindedness, fairness, generosity and integrity and by insisting on their application throughout the university as an institution. These values embody a way of being that has application well beyond academic work, into the workings of all aspects of society. And it is manifest in our engagements with each other as an intellectual community and through our collective actions in support of the common good, in how we behave towards each other as members of a community that has discovered and values its touchstones.

\section{Flying above the radar: Surviving and thriving in a (no longer) marginalised field?}

There has I think been a tendency for some physical education pedagogues to use our alleged marginality in education, kinesiology and the academy writ large to fly under the radar of the university's expectations for academic work. For example, I often hear the argument that because of the professional focus of their work, physical education teacher educators have no time and indeed no remit to engage in research and other scholarly activity. They forget, perhaps, that law, medicine, engineering and architecture, to mention just a few examples, are first and foremost professional fields also, yet few academics in these fields would entertain the possibility of being exempt from doing research. The corporatization of the university has, however, made flying under the radar less tenable since it has forced universities to consider seriously and in close up what it costs to provide, for example, programmes of physical education teacher education. In straightened financial times, the possibility of staying under the radar is less and less likely. The coming crisis that is taking shape for PETE is that, without a legitimate response to corporatization in the form of scholarship, we find ourselves unable to resist the corporate logic of the university and to be in very fragile circumstances indeed.

I suggest there is no longer any need for what we are now appropriately naming physical education and sport pedagogy academics to consider ourselves to be marginal within the 
academy. The buoyancy and vibrancy of our intellectually community, nationally in the UK and internationally, is clearly in evidence. Indeed, I have seen pedagogy researchers outperform their sport and exercise science colleagues in a number of research-led universities over the years. With recent renewed interest in 'sport pedagogy' led by Kathy Armour and AIESEP as an important and necessary sub-discipline of kinesiology, where the relevance of our research to a range of sites such as schools, sports clubs, active leisure programs and so on is acknowledged, I suggest we are increasingly well positioned to fly above the radar.

In so doing, however, we need to be prepared to confront the process of corporatization head on. In this context, I want to suggest there are ways for academics in PESP to survive and thrive in the corporatized university. The challenge is to develop ways of working that clear the space for scholarship and make it possible to engage in forms of academic work that resist and subvert corporatization. There are, I suggest, at least six strategies that allow us to clear the space for scholarship-as-resistance:

- Managing time, mundane as it may seem, is one of the basic things to be learned in order to survive and thrive in the corporatized university. This is one of the most important skills I learned in my first years working at the University of Queensland. Academics who do not learn how to do this can be pulled in too many different directions at once, such as developing a new course, while bidding for consultancy work, and so on. The downward spiral is lack of scholarly focus and a line of research on the one hand, and on the other fatigue and burnout. A key aspect of managing our time is learning to say no (politely) to projects or tasks that are not directly related to our lines of research or areas of scholarly interest and expertise. As academics we are obliged by our contracts to follow any reasonable request of a HOD; but if we believe a request to be unreasonable, we have a right to say so and a right to refuse.

- Planning collectively with small groups of colleagues with whom you share teaching and service tasks and workload is a key strategy. Taking responsibility for planning gives academics more control of their working lives. It provides opportunities, for example, to find the spaces in the yearly timetable for research and other scholarly 
activity. Planning for short (one year) and long (three years and beyond) terms can provide momentum to careers, particularly where good mentoring is available.

- Learning from others may involve a formal mentoring process or collaboration or maybe less formal processes such as a critical friend offering feedback preconference on a presentation. For example, I have been fortunate to have worked with colleagues over the years who have been generous with their time and their knowledge. Consequently, I in turn seek to assist whenever I can and see this as a major responsibility of all senior academics.

- Avoiding isolation is a closely related consequence of learning from others. Willingness to work collaboratively and learn from others is a good strategy for avoiding isolation. Managerialism works best when we are made to feel we are on our own, and weak leaders in my experience regularly use this tactic of isolation to get their own way. Working collaboratively starts from your efforts to find the touchstones of a particular group whether it be colleagues in a department or in a scholarly society. Simple initiatives such as forming a reading and discussion group, something we did to great effect in the 1980s at the University of Queensland, both with colleagues from fields other than physical education and also with groups of teachers, can often be the catalyst for collaborative projects that assist you to avoid isolation.

- Knowing how your institution works is widely underdeveloped among academics, who in my experience know very little about how our universities work as organisations, how our universities govern themselves, and their major policies for academic work and professional development. Hegemonic processes rely on people accepting that the dominant order is natural and unquestionable. Knowledge of how our institutions work can also help us preserve the democratic processes that remain in many of our universities and put them to proper work. For example, we need to take much more seriously than we typically do the process of voting for representatives on governance committees such as the university council and the faculty board.

- Networking through conferences for example is an obvious opportunity to collaborate with and learn from scholars from other institutions. Visiting other 
universities is also an important process since it provides a sense of perspective on our own institutions. Active networking in my view is a positive means of building intellectual communities, something we should do more to facilitate. Already in this SIG we are seeking ways to develop networks, particularly by organising small scale events such as specialist seminars and one day conferences that take place between annual conferences.

While these are practical and commonsensical strategies, I find that they are rarely implemented by scholars, particularly early in their careers. Why I think these strategies are crucial to making an academic career in the corporatized university is because they assist us to make the space for scholarly work, which in turn provides us with the means to resist and subvert the hegemony of corporatization. By attending to these matters we are more likely, I would argue, to survive and thrive in the corporatized university because the good practices of scholarship lead to quality publications and gain research funding, assist us with public engagement, and underpin the teaching that inspires students to want to learn. Given the pressures on academic work created by corporate culture, this infrastructure of strategies is in my view crucial.

\section{Conclusion}

My task in this Scholar Lecture has been to consider how it might be possible to make a career in PESP within a culture of corporatization of the university. In the spirit of the Scholar Lecture, I have sought to locate myself within this process of corporatization, as something I have lived increasingly over the past 30 years, by drawing on some of my own professional experiences to illustrate some aspects of corporatization. I hope to have shown through these examples that simply opposing corporatization on principle is not an adequate response.

As my examples of experiences from Deakin and Leeds Met are intended to show, there are realities flowing from corporate practices that sometimes demand a pragmatic response. In the case of Deakin, it seemed to me that the conditions that sustained a collegial culture in the single-campus university were being removed and that no amount of resistance in this case would retain them within a considerably larger, re-organised, multi-campus institution. 
My response was to move my programme of work to a new space, a School of Human Movement, where I believed then and believe now was a more favourable environment to grow and develop than a demoralised Faculty of Education. In the case of Leeds Met, having made a public critique of student fees, Vice Chancellor Lee and his Senior Executive Team promoted branding as a means of attracting enough students to compensate for rockbottom fees, using the Carnegie Faculty, of which I was Dean, as the leading brand. My Loughborough example is somewhat more personal in the sense that I had to make a decision for myself about whether I could work with integrity faced with what I saw as competing business and academic values. To report only positive findings of research in order to support sponsors would have been a form of selling-out; for me, there was no space for pragmatism in this context. However, others may have interpreted and responded to this situation differently. I could certainly understand the corporate values that prompted both the YST and the university in partnership to act in particular ways. I made a decision not to be part of that process, but that decision did not prevent the corporate partnership from continuing. I suggest that we might, collectively, as an intellectual community in this (BERA) and other organisations such as AfPE and AIESEP, need to consider how we can support colleagues who find themselves in such circumstances and, indeed, how we might respond at an organisational level.

My point in all three examples is that corporatization of the university is not all of a piece, with a simple response. Where corporatization does do violence to the academic values that many of us hold, I believe our most appropriate form of resistance is to engage in high quality scholarship, both in terms of its multi-dimensionality as outlined by Boyer, and in terms of the attitude it requires. In a field such as physical education and sport pedagogy which, for too long in my view, has flown under the university radar, it is timely for us to consider the hegemony of corporatization, to understand its contingency, and to foster collegiality and scholarship as a major form of resistance to its anti-academic effects. To do so will enable us, akin to Steck's optimists, to reclaim the university from managers and accountants; for, "If academics do not attend to the governance of their own institutions, who will?". 


\section{References}

Boyer, E. (1990) Scholarship reconsidered: priorities of the professoriate. New York: JoseyBass.

Dorling, D. (2910) Injustice: why social inequality persists. Bristol: Policy Press.

Fiegenbaum, A. (2007) The teachable moment: Feminist pedagogy and the neoliberal classroom, Review of Education, Pedagogy \& Cultural Studies, 29 (4), 337-349.

Freire, P. (1990) The pedagogy of the oppressed. New York: Seabury Press.

Gramsci, A. (1971) Selections from the prison notebooks. London: Lawrence and Wishart.

Gray, J. (2002) False dawn: The delusions of global capitalism. London: Granta.

Helmsley-Brown, J. \& Goonawardana, S. (2007) Brand harmonization within the international higher education market, Journal of Business Research, 60 (9), 942-948.

Heyman, R. (2000) Research, pedagogy and instrumental geography, Antipode, 32 (3), 292307.

Hutton, W. (2010) Them and us: Changing Britain - why we need a fair society. London: Little, Brown.

Judt, T. (2010) III fares the land. London: Allen Lane.

Kirk, D. (2011) Writing the past, writing the self, re-collecting Deakin, pp. 105-116 in R.Tinning \& K. Sirna (Eds.) Education, social justice and the legacy of Deakin University: Reflections of the Deakin diaspora. Rotterdam: Sense Publications.

Kirk, D. (2003) Communities of practice, serendipity and the discovery of 'valuable things': reflections on the social construction of physical education. Annual Scholar Lecture 
presented to the Research on Learning and Instruction in Physical Education SIG, AERA Annual Meeting, Chicago.

Kwiek, M. (2001) Globalization and higher education, Higher Education in Europe, 25 (1), 2738.

Lieberwitz, R.L. (2005) The corporatization of academic research: Whose interests are served? Paper presented to the Association of American Law School Annual Meeting.

McTaggart, R. (2011) Leftist hegemony: Personal, professional, institutional, pp. 117-134 in R.Tinning \& K. Sirna (Eds.) Education, Social Justice and the Legacy of Deakin University: Reflections of the Deakin Diaspora. Rotterdam: Sense Publications.

Meyer, H-D. (2002) The new managerialism in education management: Corporatization or organizational learning?, Journal of Educational Administration, 40 (6), 534 - 551.

Silvey, R. (2002) Sweatshops and the corporatization of the university, Gender, Place and Culture, 9 (2), 201-207.

Steck, H. (2003) Corporatization of the university: Seeking conceptual clarity, The ANNALS of the American Academy of Political and Social Science, 585: 66-83.

Tuchman, G. (2009) Wannabe U: Inside the corporate university. Chicago University Press.

\section{Acknowledgement:}

I would like to thank Professor Kim Oliver and Professor Patricia Vertinsky for their very helpful and constructive feedback on an earlier draft of this paper. Any shortcomings that remain are, of course, my responsibility. 